\title{
The Mixing Degree of Mixed Ownership Enterprises and the Innovation of Corporate Governance
}

\author{
Chen Ying ${ }^{1,2, a *}$ \\ ${ }^{1} \mathrm{Fu}$ Zhou University, China \\ ${ }^{2}$ Fujian Commercial College, China \\ a602042290@qq.com
}

Keywords: Mixed Ownership Enterprises; Degree of Mixing; Corporate Governance; Innovation

\begin{abstract}
This article selected 1000 mixed ownership enterprises as samples from Shenzhen and Shanghai Stock Market in 2015. To the mixed ownership of the enterprise mixed degree as the standard, classification of the nature of the first major shareholders of the 1000 listing Corporation. The governance problems of two kinds of mixed ownership enterprises with high degree of mixing and low mixing ratio are analyzed, and on this basis, it discusses the innovation and optimization of the mixed ownership enterprise management.
\end{abstract}

\section{Introduction}

The state issued "The guidance on deepening the reform of state-owned enterprise" in September 13, 2015. That puts forward "developing a mixed ownership economy vigorously, and encouraging state-owned capital in a variety of ways in non state owned enterprises." Countries from the promotion of non state-owned enterprises in shares of state-owned enterprises, to encourage state-owned capital now take the initiative to enter the non state-owned enterprises. We can see that state promote the development of mixed ownership enterprises from the policy level more actively. On the one hand, mixed ownership enterprises can make an inventory of state-owned capital, on the other hand, for the state-owned enterprises to inject more vitality. Therefore, the mixed ownership enterprises have become one of the most obvious signs of the reform of state-owned enterprises in China at this stage. Mixed ownership's key-point is not in the "mix", but in the "close". From the point of view of state-owned enterprises, the loss of state-owned assets; from the perspective of social capital, but also worried that they lack the right to say, to be controlled by state-owned enterprise. A balance of different interests to achieve win-win interests' distribution is important for the mixed ownership enterprises. The corporate governance structure of effective and equal protection can achieve win-win benefits distribution. The development of mixed ownership enterprises is an innovative attempt in the background of our system of public ownership, but how to deal with the equity allocation of shareholders of different nature in the mixed ownership enterprises, improve the efficiency of corporate governance, and thus promote the performance of enterprises is also an innovative challenge.

The studying of mixed ownership is in several stages from careful exploration to it to study in the compatibility of mixed ownership and socialist system, to demonstrate the feasibility of this kind of enterprises and in the process of practice results to the present research is mainly concentrated in all how perfectly mixed business development. From a different perspective to explore the mixed ownership reform of corporate governance, is generally believed that ownership structure has significant impact on corporate governance, but the conclusion is that the proportion of state-owned shares is too large is the main reason leading to inefficient corporate governance, corporate governance and no design on different ownership structure of classification discussion. Based on this, this paper will be mixed ownership of corporate equity mixed empirical research based on the different degree of mixing enterprise innovation on its corporate governance mechanism construction and analysis, provides a useful theoretical reference for the reform of mixed ownership enterprises. 


\section{Mixed Degree of Mixed Ownership Enterprise Analysis}

In this paper, the ownership structure of mixed ownership enterprises is described by the index of mixed degree. In the ownership structure of the mixed ownership enterprises can be composed of state-owned shares and non state-owned shares, the addition of two shares to $100 \%$.

Assuming the proportion of state-owned shares accounted for all of the shares is $E_{g}$, the proportion of non state-owned shares accounted for all of the shares is $E_{p}$. $E_{g}$ and $E_{p}$ will be greater as the denominator, as small molecules, the ratio of mixed $\mathrm{M}$.

$$
\begin{aligned}
& \text { if } E_{g}>E_{p}, M_{g p}=E_{p} / E_{g} \text {; } \\
& \text { if } E_{p}>E_{g}, M_{p g}=E_{g} / E_{p}
\end{aligned}
$$

Therefore, the $\mathrm{M}$ value is close to 1, the higher the degree of mixing, the $\mathrm{M}$ value more close to 0 , the lower the degree of mixing. We will be divided into three mixed interval were discussed, when $M \in[1,2 / 3]$, which belongs to the mixed ownership enterprises mixed high degree; when $M \in$ $(2 / 3,1 / 3]$, belong to mixed ownership enterprises; degree of mixing medium when $M \in(1 / 3,0)$, belongs to the mixed ownership of the enterprise is low. Because $M$ only represents the degree of mixing, we can not distinguish between state-owned shares or non state-owned shares accounted for the proportion of. So when the stock proportion is larger than the proportion of state-owned shares, the mixing degree with $\mathrm{M}_{\mathrm{gp}}$ said, on the other hand, is represented by $\mathrm{M}_{\mathrm{pg}}$. If $\mathrm{M}_{\mathrm{gp}}=0.25$, the proportion of state-owned shares accounted for $80 \%$, the proportion of non state-owned shares accounted for $20 \%$; if $\mathrm{M}_{\mathrm{pg}}=0.25$, then the proportion of non state owned shares is $80 \%$, the proportion of state-owned shares is $20 \%$. The mixture of these two cases is the same, but the former is the degree of nationalization is high, but the degree of nationalization is low, and the latter is a high degree of nationalization, but the degree of nationalization is low. Because this paper is a sample of listed companies, the shareholders of the data only announced the name of the top ten shareholders, holding shares and shares of the category. Therefore, we will study these ten major shareholders of the data to study the mixed ownership of enterprises in the mixed situation.

Enterprise Sample Collection. This paper mainly on the 2015 Shanghai and Shenzhen stock exchange in mixed ownership enterprises for statistical sampling, from which 1000 listed companies as the samples, the main data from the Wind database and Cninf. Since the mixed ownership enterprises are originated from the state-owned enterprise restructuring, so we have a certain orientation in the process of collecting samples, the main extraction is the state-owned enterprises after the restructuring of enterprises. Reform is the essence of ownership, it is state-owned enterprises or state-owned holding enterprises to introduce non state-owned capital through the sale of state-owned assets and other ways to increase their investment, in order to realize the part of non nationalization.

Analysis on the Nature of the Shareholders. In the sample, we found that $68.6 \%$ of the enterprises, which is the largest shareholder of 683 companies is the nature of the state, only $31.7 \%$ of the first shareholders of the enterprise as a non state-owned nature, as shown in Table. 1.

Table. 1 The distribution of the nature of the largest shareholder

\begin{tabular}{ccc}
\hline & The number of enterprises & Proportion of sample \\
\hline $\begin{array}{c}\text { The largest shareholder is the } \\
\text { state-owned shareholder }\end{array}$ & 683 & $68.3 \%$ \\
$\begin{array}{c}\text { The largest shareholder is a } \\
\text { non - state - owned } \\
\text { shareholder } \\
\text { Total }\end{array}$ & 317 & $31.7 \%$ \\
\hline
\end{tabular}

Detailed analysis of the first major shareholders in the sample data obtained, including state-owned enterprises as the first major shareholders accounted for 51.3\%; nature of the largest shareholder is the state-owned asset management company, accounting for $14.5 \%$; enterprise employees as the first major shareholders of the sample enterprises accounted for 9.4\%; private enterprises and domestic natural persons of the first major shareholders accounted for $9.4 \%$ and $7.1 \%$; 
the first major shareholders for the managers of the proportion of 5.9\%; government agencies for the first major shareholders accounted for $2.5 \%$; foreign enterprises as the first major shareholder is $2 \%$; in other cases, such as non bank financial institutions, collective enterprises, universities, scientific research institutions such as the first major shareholders accounted for 1.3\%.( Table.2)

Table. 2 The proportion of the specific identity of the first major shareholders

\begin{tabular}{ccc}
\hline Specific Identity & The number of enterprises & Proportion \\
\hline State-owned enterprises & 513 & $51.30 \%$ \\
State-owned asset management & 145 & $14.50 \%$ \\
company & & \\
Employees & 94 & $9.40 \%$ \\
Private Enterprises & 71 & $7.10 \%$ \\
Domestic natural persons & 60 & $6.00 \%$ \\
Managers & 59 & $5.90 \%$ \\
Government Agencies & 25 & $2.50 \%$ \\
Foreign Enterprises & 20 & $2.00 \%$ \\
Others & 13 & $1.30 \%$ \\
Total & 1000 & $100.00 \%$ \\
\hline
\end{tabular}

From the above data, we can see that in the $31.7 \%$ largest shareholder of non state-owned shareholders of enterprises in the management of employees and the management of the first major shareholders accounted for $15.3 \%$ of the proportion. According to this, we can infer that in the last round of the restructuring process of state-owned enterprises, the internal people that managers and employees are the most important to dilute the strength of state-owned assets, rather than the external non state owned enterprises. Mixed ownership of corporate governance from the original internal control problem for large-scale insider ownership, this is a sense of internal control will be legalized, so as to further increase the complexity of the mixed ownership of corporate governance. This result with the concerns of the two sides, not only the state-owned enterprise leaders worry about the loss of state assets and the non state-owned enterprises to introduce external hold cautious attitude, the attitude of non state-owned enterprise external cooperation with state-owned enterprises is not positive. As shown in Figure. 1, from the figure we see only $30 \%$ of small and medium-sized enterprises in the enterprise have a more positive attitude toward cooperation with state-owned enterprises, small and medium-sized enterprises accounted for more than half of the said does not consider cooperation with the state-owned enterprises, and $14 \%$ enterprises and state-owned enterprises even reluctant to work together.

Fig.1 The attitude of small enterprises to participate in mixed ownership economy

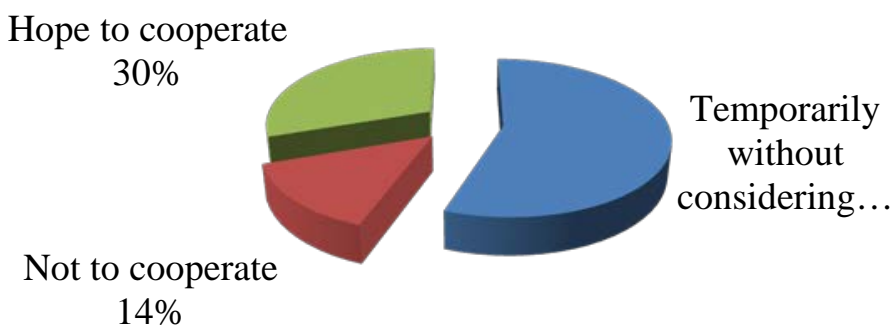

Data Sources: 2015 mixed ownership and SME development survey database, China Association of small and medium enterprises

From the above analysis, we can see that the national mixed ownership reform in these years is not significant, in-depth analysis of its causes, the problem is not involved in the reform of the reform of mixed ownership enterprises corporate governance mechanism. The reform of corporate governance has not kept up, there will be no way to solve some important problems, such as how to protect the interests of small and medium-sized enterprises in mixed ownership enterprises, how to prevent the loss of state assets in the reform, how to improve the management efficiency of enterprises of mixed ownership. And these issues are related to the construction of mutual trust mechanism in the mixed ownership enterprises. No corporate governance mechanism supporting reform and innovation will 
lead to a lack of cooperation between the two sides, the two sides can not control the management of the enterprise after the mixed ownership of corporate governance, mutual distrust.

Mixed Degree Analysis. Next, we study the mixing degree of the 1000 sample enterprises. According to the specific identity of the first major shareholder to divide nine types of mixed ownership enterprises, according to the shareholding ratio of the 1000 sample companies top ten shareholders to calculate the various types of enterprises and the weighted average of $\mathbf{E}_{\mathbf{g}}$ and $\mathbf{E}_{\mathbf{p}}$, as shown in Table.3.

Table.3 The proportion of state-owned and non-state -owned shares

\begin{tabular}{ccc}
\hline The identity of the largest shareholder & $\mathbf{E}_{\mathbf{g}}$ & $\mathbf{E}_{\mathbf{p}}$ \\
\hline State-owned enterprises & $73.20 \%$ & $26.80 \%$ \\
State-owned asset management company & $68.45 \%$ & $31.55 \%$ \\
Employees & $11.20 \%$ & $88.80 \%$ \\
Private Enterprises & $11.80 \%$ & $88.20 \%$ \\
Domestic natural persons & $9.44 \%$ & $90.56 \%$ \\
Managers & $4.10 \%$ & $95.90 \%$ \\
Government Agencies & $80.33 \%$ & $19.67 \%$ \\
Foreign Enterprises & $19.21 \%$ & $80.79 \%$ \\
Others & $42.31 \%$ & $57.69 \%$ \\
\hline
\end{tabular}

On this basis, then calculate the mixed index of each type of enterprise $\mathrm{M}$, as shown in Table.4.

Table. 4 Mixed Degree of Sample

\begin{tabular}{ccc}
\hline The identity of the largest shareholder & Mixed Degree & Mixed Degree Grade \\
\hline State-owned enterprises & $\mathrm{M}_{\mathrm{gp}}=0.37$ & Medium \\
State-owned asset management company & $\mathrm{M}_{\mathrm{gp}}=0.46$ & Medium \\
Employees & $\mathrm{M}_{\mathrm{pg}}=0.13$ & Low \\
Private Enterprises & $\mathrm{M}_{\mathrm{pg}}=0.10$ & Low \\
Domestic natural persons & $\mathrm{M}_{\mathrm{pg}}=0.10$ & Low \\
Managers & $\mathrm{M}_{\mathrm{pg}}=0.04$ & Low \\
Government Agencies & $\mathrm{M}_{\mathrm{gp}}=0.24$ & Low \\
Foreign Enterprises & $\mathrm{M}_{\mathrm{pg}}=0.24$ & Low \\
Others & $\mathrm{M}_{\mathrm{pg}}=0.73$ & High \\
\hline
\end{tabular}

In order to further analyze the degree of mixing, we need to further calculate the number of $\mathrm{M}$ arithmetic mean and weighted average. The average number of $\mathrm{M}$ is the Table. 4 of the various types of groups in the table $\mathrm{M}$ mean, the average number of $\mathrm{M}$ arithmetic. And the weighted average number of $\mathbf{M}$ is the $\mathbf{E}_{\mathbf{g}}$ and $\mathbf{E}_{\mathbf{p}}$ in Table.3 weighted average, and then come to the weighted average number of $\mathrm{M}$. The specific calculation results are shown in Table.5.

Table.5 The Arithmetic Average and the Weighted Average of M

\section{Arithmetic Average of $M$}

0.27

\section{Weighted Average of $M$}

0.88

From Table.5, we can see that Arithmetic average and weighted average of $\mathrm{M}$ is difference. This is because the management, domestic natural persons and private enterprises as the largest shareholder of the enterprise's M values are relatively low, that these types of state-owned shares in the enterprise are very low proportion, so the low $\mathrm{M}$ arithmetic average. But the number of enterprises in the total number of enterprises in the total amount is not large, so the impact on the weighted average is not large. This is the main reason for the gap between the average number of $\mathrm{M}$ and the weighted average. From all kinds of enterprises, the mixed ownership enterprises in China's $\mathrm{M}$ are in the moderate to inferior. But $\mathrm{M}$ is high from the weighted average. Moreover, we find that in the mixed ownership enterprises in the enterprise's internal mixed with the country is the most common, private enterprises, foreign enterprises and other countries mixed with the situation is very small. This also from a side exposed the mixed ownership of enterprises in the governance have some of the problems.

Analysis of Company Performance. We classified the earnings per share and return on net assets of 1000 sample companies. As shown in Table.6, the largest shareholder of the identity of the other mixed ownership enterprises, the highest rate of return on equity, and this kind of enterprise is also relatively high degree of mixing. From the Table.6 we can infer that the high degree of mixing of the 
mixed ownership enterprise performance to be relatively better than the low degree of mixing of the mixed ownership enterprises.

Table.6 Comparison of Mixed Degree degree and company performance

\begin{tabular}{|c|c|c|c|c|}
\hline $\begin{array}{l}\text { The identity of the largest } \\
\text { shareholder }\end{array}$ & $\begin{array}{l}\text { Mixed Degree } \\
\text { Grade }\end{array}$ & Proportion of Sample & $\begin{array}{c}\text { EPS } \\
\text { (yuan) }\end{array}$ & $\begin{array}{l}\mathrm{ROE} \\
(\%)\end{array}$ \\
\hline State-owned enterprises & Medium & $51.30 \%$ & 0.2 & 7.09 \\
\hline $\begin{array}{c}\text { State-owned asset } \\
\text { management company }\end{array}$ & Medium & $14.50 \%$ & 0.21 & 7.34 \\
\hline Employees & Low & $9.40 \%$ & 0.17 & 5.56 \\
\hline Private Enterprises & Low & $7.10 \%$ & 0.12 & 5.02 \\
\hline Domestic natural persons & Low & $6.00 \%$ & 0.19 & 6.83 \\
\hline Managers & Low & $5.90 \%$ & 0.1 & 4.32 \\
\hline Government Agencies & Low & $2.50 \%$ & 0.17 & 6.21 \\
\hline Foreign Enterprises & Low & $2.00 \%$ & 0.15 & 5.51 \\
\hline Others & High & $1.30 \%$ & 0.34 & 11.09 \\
\hline
\end{tabular}

\section{Innovation of High M mixed Ownership Corporate Governance}

When the value of $M$ is between 1 to $2 / 3$, belong to the mixed ownership of the high $M$. $M$ high note in the top ten shareholders of state-owned has a relatively close to the proportion of shareholders and non state-owned shareholders, such as the advantages of mutual checks and balances between state-owned and non-state shareholders. It will produce a certain governance issues when the directors have no absolute right to decision-making.

Governance Issues. In the above analysis, we can see a high degree of mixed ownership of corporate performance is relatively high, but the high degree of mixing in corporate governance also has some adverse effects. Since there is no absolute control of the shareholders, each shareholder is the identity of the shares, the board of directors have no absolute decision-making power. So when the decision problem management major differences, it is difficult to effectively discuss solutions, very prone to haggling and shifting of responsibilities, which is the internal strife between shareholders. Each shareholder will judge the issue from its own interests, may be after a long period of bargaining or no way to reach a unified opinion. For the listed companies, this is likely to lead to miss the opportunities or delays in the timing.

Governance Innovation. In view of this situation, the establishment of a strategic committee in the enterprise is to solve the internal strife of shareholders. The position of the strategic committee is a decision-making body or a cross functional coordination mechanism under the leadership of the board of directors. Its main duty is to analyze the strategy and planning for the long-term development of the business, and follow up the implementation, evaluation and control strategy, and the strategy committee considered the results will have a great influence on the decision of the board of directors. A member of the strategy committee candidates can be selected from the internal and external, such as enterprise executives, representatives of the employees or independent directors, outside the enterprise experienced industry experts, bank representatives or important clients. Members can be diverse, but each has its irreplaceable. This can not only ensure the fairness of the decision-making, but also can ensure the scientific and feasibility of decision-making.

\section{Innovation of Low M mixed Ownership Corporate Governance}

When the value of $M$ between 1/3 to 0, belong to the mixed ownership of the low mixed ownership enterprises. There are two kinds of situations in the mixed ownership enterprises, one is the high proportion of state-owned shares in the total shares, the other is not the proportion of state-owned shares in the total share of the total. Although two cases belong to the mixed degree is low, but not high proportion of state-owned shares is a special case, because the non state-owned shares are not concentrated in a non state-owned shareholders, but scattered in a number of non state-owned 
enterprises or corporate managers and other types of shareholders. Therefore, we only discuss the first case

Governance Issues. Insider Control Problem. The relationship between principal and agent makes the owner and operator separate. But the information asymmetry between the owners and operators and supervision is not in place and other issues, leading operators to become the enterprise's internal people, thus the emergence of reverse selection and other acts. Because of the basic economic system of our country is public ownership, and the public ownership is not the existence of independent property rights, but the ownership of state-owned property rights, in essence, is the owner's absence. In this way, the state-owned property rights cannot be the same as private ownership by its owners to choose the right agent (operators), and its supervision. In the state as the representative of the state-owned property rights and agents (operators) must have a link, that is, government officials, we call them as external agents, operators called internal agents. There are two levels of principal-agent relationships between them, as shown in Figure 2.

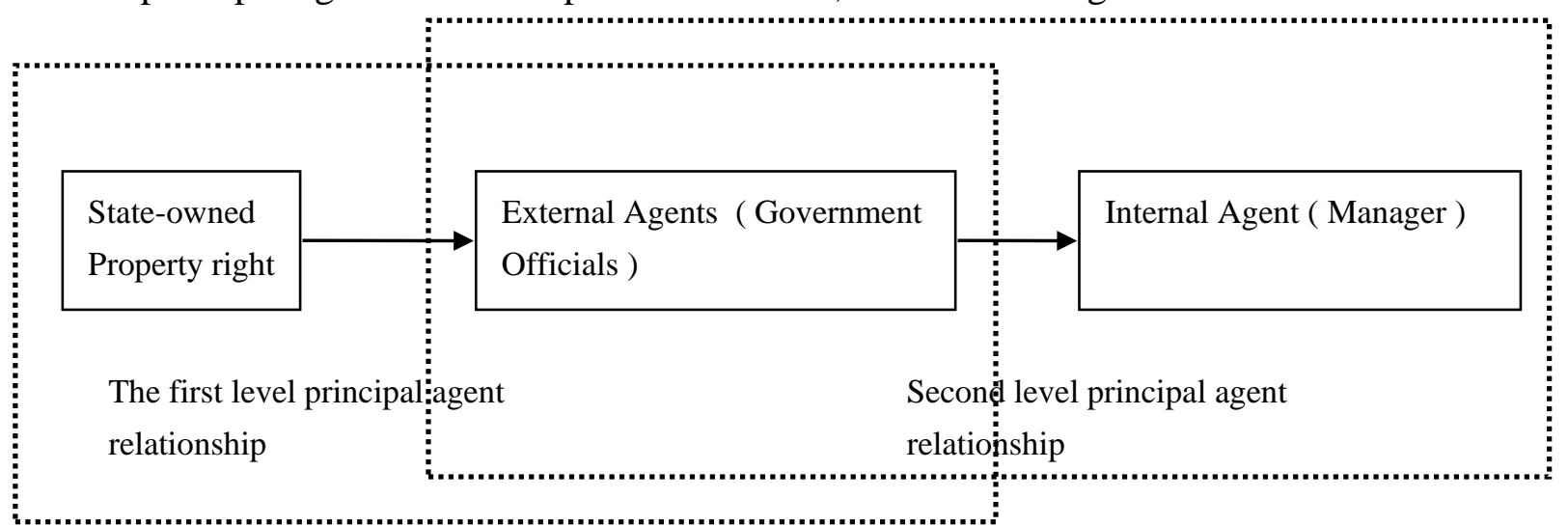

Fig. 2 Two Level Principal-Agent Relationship of State-Owned Listed Companies

Therefore, mixed ownership enterprises' proportion of state-owned shares in the high proportion of which "insider control" problem will be more complex. External agents (government officials) will become "insiders", internal agents (managers) may also become "insiders", and they can become "insider". The "insider control" will have the following three forms: first, when the external agent (government officials) to become the "insider", they may neglect the profit target of the enterprise and to allow enterprises to take over the policy target, or using a variety of methods to carry on the illegal occupation of state-owned assets. Second, when the internal agent (operators) to become the "insider", they may use their power and information asymmetry of misappropriation of state assets, resulting in a loss of state assets. Finally, if the external agents (government officials) and the internal agents (operators) collusion become "insiders", they may be a conspiracy or moral hazard and other issues.

There are two kinds of situations can lead to "insider control" is more serious, one is the chairman and general manager of duality, and the other is a member of the board of directors of listed companies basically as a major shareholder. The state-owned shares accounted for a high proportion of mixed ownership enterprises are state-owned holding company, we also found in the investigation board in the listed company will have $76 \%$ members are appointed by the shareholders, and in state-owned enterprises Chinese corporate shares shareholders choose members of the board of directors of all $48 \%$ state-owned shareholders the members of the board of directors accounted for $21 \%$, therefore, two ways to combine the national selection of members of the board of directors accounted for up to $70 \%$ of the total number. This leads to the difficulty of the board of directors and managers to form an effective incentive and restraint mechanism.

Interests Protection of Non State Owned Shareholders. In the case of mixed ownership enterprises, the proportion of state-owned shares is too high, there will be an unavoidable problem, that is, the protection of the interests of non state shareholders. Mixed ownership enterprises although many advantages, but many non state-owned enterprises are still in wait-and-see state, a large part of the reason is that they worry about the shares of state-owned enterprises, as the stock does not account for advantages compared with state-owned enterprises, their own interests will be violated or power is overhead, thus lost the right to speak. The expropriation of the interests of the non - state small 
shareholders by the State - owned shares is often expressed as the diversification of the passive target to seize the interests of the minority shareholders. The diversification of business objectives is the inevitable result of corporate social responsibility. There are two forms of diversification of business objectives, one is active, and one is passive. Passive target diversification is the policy burden that enterprises are forced to bear under the pressure of the outside world. In the mixed ownership of state-owned shares, the government is the actual controller, which provides the necessary conditions for the government to intervene in the business objectives. Compared with the non state owned shareholders, the government is more inclined to maximize the social welfare. Policy burden too much of an increase in the operating costs of enterprises, damage the economic efficiency of enterprises, on the other hand, the diversification of information asymmetry between the principal and agent is more serious, more clients for the agent's supervision difficult, thus reducing the efficiency of governance.

Governance Innovation. Optimize the Ownership Structure. When there is a high degree of concentration of ownership in the mixed ownership, it is highly likely that small and medium shareholders will be difficult to balance large shareholders led to the loss of discourse. In the case of low degree of mixing, and the proportion of state-owned shares is too high, this problem is more likely to appear. So diversified mixed ownership enterprises through investment to reduce the proportion of state-owned shares, decentralized ownership, so as to form the joint supervision of common control and management pattern, to avoid the marginalization of small and medium shareholders status. The ownership structure optimization can be realized through the following forms:

Through Increase the Capital to the Reduction of State-Owned Shares. Through allotment or issuance of new shares to expand the company's total share capital, the share capital must be extended to non-state-owned nature, so as to achieve the purpose of dilution of the proportion of state-owned shares.

Separation of the State-Owned Projects. Some competitive state-owned capital projects a huge amount of small and medium-sized enterprises alone or Baotuan are difficult to achieve holdings. So for this type of project, you can take a split approach to encourage no-state-owned company.

Implementation of Employee Stock Ownership. Employee stock ownership method can optimize the ownership structure of enterprises, and the relative concentration of state-owned shares into employee stock. In addition, employee stock ownership can also help the state-owned enterprises in the restructuring process of a smooth transition, because some state-owned enterprises have private capital to enter, resulting in emotional hard to accept employees. In order to achieve a smooth transition in the management of state-owned enterprises in the management, employee stock ownership is a good method, can help enterprises to retain core talents.

Improve the Governance Mechanism of the Board of Directors. A sound board of directors governance mechanism is the key to avoid "insider control". If there is non state-owned capital to enter the same time, the board of directors is still in the hands of state-owned shareholders, then it will reduce the enthusiasm of non-state capital to participate in mixed ownership enterprises. On the one hand, we can learn from Singapore's Model of Temase. Establish a strong board of directors as the core of corporate governance structure. Directors of the board of directors, independent directors and executive directors of three kinds of independent directors, by the government officials, business leaders, private parties three party members together. Most of the directors are external independent directors, who are generally held by the ability to cross the border, some of them from the private sector, or from multinational companies, in the enterprise management has a wealth of experience. The executive director is responsible for the implementation of specific decisions. This will not only reduce the board of directors of the board of directors to intervene too much to better achieve the separation of decision-making and implementation. In the mixed ownership enterprises of our country's board of directors can increase the proportion of independent directors, so that the number of independent directors accounted for more than half of the proportion of independent directors, because is not a shareholder's agent, but the agent of all the shareholders. Shareholders will be able to 
adopt a cumulative voting system to ensure that non state shareholders can enter the board of directors. It is better to reduce the number of executive directors, preferably within 2.

The Establishment of a Standardized System of Professional Managers. The first thing is to reduce the government of mixed ownership enterprises operator selection intervention, manager selection and appointment must be open recruitment, talent through the examination to determine the trial. Secondly, under the premise of clarifying the functions of the board of directors, the independence and initiative of the operators are highly valued. In the process of establishing the market of professional managers, the establishment of professional managers access and rating agencies, in the formation of the government led by the government, the industry association is responsible for the. Access conditions and price standard system design must adapt to China's national conditions, and then in accordance with the access conditions of professional managers for approval, and regularly to its level of certification.In addition, in the manager market, the credit mechanism should be set up to prevent managers from damaging the interests of shareholders, resulting in the loss of state-owned assets. For example, the establishment of professional managers of credit files, credit files on the issue of professional managers to clean up. The development of professional managers of professional standards, pay level, job consumption, equity and dividends and other incentives to strictly regulate the management, and establish a regulatory system, the professional manager of the moral behavior of the punishment.

\section{Summary}

The development of mixed ownership enterprises, is not only an important direction of state-owned enterprise reform, but also an important strategic path for the transformation and upgrading of smes. But from the current situation of the development of mixed ownership enterprises in our country, the process of reform is not optimistic, there are many problems in the reform. Mixed ownership enterprises of mixed ownership enterprises is not high, most of the mixture is mixed between an enterprise and state owned enterprises and people, and from the external non state-owned capital mixed with state-owned enterprises accounted for less. Small and medium-sized enterprises to participate in mixed ownership reform, mainly top-level design is not in place, especially the corporate governance mechanism is not perfect, so that SMEs are involved in the reform will lose the right to speak, to damage their own interests concern. Because of the different governance problems caused by different mixing degree, we can design the innovation and optimization scheme of the mixed ownership enterprises according to the different mixing degree.

Mixed ownership enterprises of a high degree can be used to establish the strategic committee to resolve the friction problems so as to improve the efficiency of corporate governance. For internal control, mixed ownership mixed degree produced by lower and non state-owned shareholders to protect the interests of the problem can be solved by optimizing ownership structure, board governance mechanism, establish occupation managers system norms and enhance the positive effect of policy objectives etc..

\section{References}

[1] Chong A, F Lopez de Silances. The Truth about Privatization in Latin America. California: Stanford University Press, 2005

[2] De Bettignies J E, T Ross. Public Private Partnership and the Privatization of Financing: An Incomplete Contracts Approach. Vancouver: UBC Vancouver, 2007

[3] Iossa E, D Martimort. The Economics of Public-Private Partnerships, London: Brunel University, 2008

[4] Li Zengfu, Lin Shengtian, Lian Jun. Earnings management [J]. Journal of engineering state holding, institutional investors and real activities, 2013 (3) 
[5] Wu Qiuming Chen Ying. Science and management [J].Analysis on the Governance Dilemma of state owned Listed Companies in China based on principal agent theory: 2015 (5). 